\title{
COMMUNICATIONS
}

\section{EXPERIMENTS ON CANINE CORNEAL DONOR MATERIAL STORED IN LIQUID NITROGEN*†}

\author{
BY \\ F. O. MUELLER \\ From the Corneal Research Unit, Westminster-Moorfields Eye Bank at the Royal Veterinary \\ College, London.
}

TECHNIQUES of preserving the cornea including storage at very low temperature or by freeze-drying have proved to be satisfactory for lamellar grafts (King, 1958; Hénaff, 1960; Sweebe and Dohlman, 1961). The results of Eastcott and co-workers, of Rycroft, and of Stocker when grafting the full-thickness of corneal donor material stored at low temperatures and by other methods were disappointing (Eastcott, Cross, Leigh, and North, 1954; Rycroft, 1957; Stocker, Matton, Eiring, Georgiade, and Georgiade, 1960).

In 1959 dimethyl-sulphoxide (DMSO) was introduced into low-temperature biology (Lovelock and Bishop, 1959). The first successes with this protective agent in studies on corneal preservation in vitro for full-thickness keratoplasty were reported by Smith and co-workers in 1963, and their excellent results revived some enthusiasm in long-term corneal preservation (Smith, Ashwood-Smith, and Young, 1963). Kaufman and associates reported high success rates of full-thickness grafts with human material stored at $-197^{\circ} \mathrm{C}$. and suspended in 7.5 per cent. DMSO (Capella, Kaufman, and Robbins, 1965; Kaufman, Escapini, Capella, Robbins, and Kaplan, 1966). Other workers published their results with full-thickness keratoplasty in rabbits and in man using 7.5 and 14 per cent. DMSO and various rates of cooling (Mueller and Smith, 1963; Mueller, Casey, and Trevor-Roper, 1964; Mueller, O’Neill, and Trevor-Roper, 1967).

One of the results of a clinical trial of grafting fresh and frozen corneal donor tissue was the assessment of endothelial viability by the nitroblue-tetrazolium technique (Pearse, 1960; O'Neill, Mueller, and Trevor-Roper, 1967). The histochemical results on thawedout human corneae were suggestive of severe endothelial changes when compared with fresh material, whereas grafting such thawed-out material gave a high success rate of clear grafts.

These contrary findings provoked further research, in particular into the thawing rates of corneal donor material. The results of these experiments are presented in this paper.

\section{Source of Donor Eyes}

\section{Animals and Methods}

Dogs supplied by dealers were killed by intravenous injection of $8 \mathrm{ml}$. Trinaven $\ddagger$ (Phenobarbitone sodium grain 3 per $\mathrm{ml}$.). The eyes were removed immediately after the death of the animal and were stored in clean screw-topped glass jars. These were kept at room temperature $\left(a t+18^{\circ} \mathrm{C}\right.$.) and cooled within 3 hours or stored in the refrigerator at $+4^{\circ} \mathrm{C}$. and used within 36 hours of the death of the animal.

\footnotetext{
* Received for publication March 20, 1968

+ Address for reprints: The Royal Free Hospital, London, W.C.1.

$\ddagger$ Asta-Hewlett Ltd., Watford.
} 
Twelve human eyes were obtained from the Westminster-Moorfields Eye Bank where they had been kept for 4 to 12 hours in sterile dry jars or in sterile liquid paraffin at $+4^{\circ} \mathrm{C}$.

\section{Preparation of Solutions and of Corneae for Freezing}

Sterile stock-solutions were made up containing 50 per cent. calf serum and 50 per cent. tissue culture medium $199(\mathrm{v} / \mathrm{v})$; solutions containing an additional 6 per cent. polyvinyl pyrrolidone,* average molecular weight 40.000 or average molecular weight 10.000 , were also stored at a pH of $7 \cdot 2$ to $7 \cdot 3$ at $+4^{\circ} \mathrm{C}$. Media containing $8,10,12$, or 14 per cent. DMSO* were made up in stocksolutions immediately before cooling the corneae to $-197^{\circ} \mathrm{C}$. The cornea with a rim of sclera was cut from the intact donor eye and the adherent ciliary body, iris, and lens were carefully removed; each specimen was kept in stock-solution at $+10^{\circ} \mathrm{C}$. until all the corneae of one experiment were ready to be suspended and cooled.

The cornea was submerged inside an aluminium vessel $\dagger$ measuring $30 \times 49 \mathrm{~mm}$. containing $10 \mathrm{ml}$. of a well-mixed DMSO solution at $+2^{\circ} \mathrm{C}$. Each minute the cornea, with its endothelium facing upwards, was gripped by its scleral rim and gently moved to obtain quickly a DMSO equilibrium between cornea and medium. After 6 minutes the cornea was turned endothelium downwards so that the scleral rim rested against the bottom of the aluminium vessel, and the fluid was aspirated.

In the first two series of experiments, $3 \mathrm{ml}$. of excess medium were aspirated so that the suspending medium still covered the cornea; in the third series of experiments, $9.5 \mathrm{ml}$. were aspirated and only the scleral rim remained submerged in fluid. In the final trials all the available medium was removed or the specimen was taken out of the suspending medium and transferred into a dry pre-cooled aluminium container. In all experiments the cornea maintained its normal shape. The vessel was then closed with a plastic lid and immediately placed into the alcohol bath of the cooler.

\section{Freezing and Techniques of Thawing}

All containers were cooled in the alcohol bath of a Matburn Freezer at similar rates. Cooling proceeded slowly at $1^{\circ} \mathrm{C}$. $/ \mathrm{min}$. down to $-15^{\circ} \mathrm{C}$. and then at $5^{\circ} \mathrm{C}$. $/ \mathrm{min}$. from -15 to $-60^{\circ} \mathrm{C}$. The vessels were then quickly transferred into a Linde liquid nitrogen refrigerator and kept at $-197^{\circ} \mathrm{C}$. for 3 to 7 days. During thawing the container was taken from the refrigerator, and a hot moist cloth was pressed against the lid until the plastic became pliable and the lid could be removed; this took about 8 seconds. In the early experiments, when the cornea had been submerged in $7.0 \mathrm{ml}$. medium, the open container was held in a waterbath of $+50^{\circ} \mathrm{C}$. and was taken out before all the ice had melted to prevent overheating. In the later experiments the vessel containing $7 \mathrm{ml}$. medium was placed in a waterbath of $+50^{\circ} \mathrm{C}$. and after 10 seconds $10 \mathrm{ml}$. stock-solution were added. Corneae banked in $0.5 \mathrm{ml}$. medium were warmed in their containers in the bare hand and $10 \mathrm{ml}$. stock-solution of $+10^{\circ} \mathrm{C}$. were added after some seconds. Vessels containing corneae banked in vapour were also warmed in the hand and stock-solution of about $+8^{\circ} \mathrm{C}$. was added. The corneae were gently moved in the fluid to prevent ice formation and to speed thawing. Finally all the corneae were suspended in stock-solution of about +10 to $+20^{\circ} \mathrm{C}$. for 6 minutes.

\section{Estimation of Viability of Corneal Endothelial Cells}

After thawing the cornea was placed on a Latex rubber ring and the endothelial concavity facing upwards was filled with $0.8 \mathrm{ml}$. of the nitroblue-tetrazolium incubation medium developed by $O$ 'Neill (see below). After 90 minutes of incubation at $+37^{\circ} \mathrm{C}$ the specimen was fixed in glacial acetic acid alcohol (glacial acetic acid 30 parts, absolute ethanol 70 parts) for at least 24 hours.

* Sigma, London.

† Metal Box Company, London. 
The epithelium was removed and a $9 \mathrm{~mm}$. central disc was cut with a corneal trephine and suspended in diluted ethanol ( 30 per cent.) for 30 minutes. The disc was then transferred into a solution of glycerol-ethanol (glycerol 70 parts, absolute ethanol 29 parts, Teepol 1 part) for at least 3 hours. Finally, the full-thickness corneal disc was mounted in absolute glycerol and its endothelium was examined microscopically. Cells which had suffered damage showed cytoplasmic diformazan deposits and therefore stained blue. Endothelium of treated corneae was compared with that of fresh untreated corneae and the viability assessed.

The incubation medium for all corneae was made up as follows and was kept at $+37^{\circ} \mathrm{C}$. for repeated use:

Sodium $\beta-\mathrm{OH}$ butyrate

$\beta$-Diphosphopyridine nucleotide

Nitroblue-tetrazolium

Trizma buffer containing 5 per cent. polyvinyl pyrrolidone 40 and stored at pH 6.91 at $+37^{\circ} \mathrm{C}$.*

\section{From Unfrozen Corneae kept in Vapour}

\section{Results}

Pairs of donor eyes were kept at $+18^{\circ} \mathrm{C}$. for up to 3 hours, others were stored at $+4^{\circ} \mathrm{C}$. for about 24 hours. The corneae were dissected from the intact donor eyes, incubated, fixed, and mounted.

Apart from a few stained cells, the endothelium of the corneae was invisible and mechanical damage with the bristles of a brush was an easy way of ascertaining its presence (see Fig. 1A and B). The few stained cells were scattered over the corneal disc and showed cytoplasmic diformazan granules surrounding the cell nucleus; outlines of these cells were irregular and appeared crenated.

Differentiation between corneae stored for 3 hours or for 24 hours was not possible.
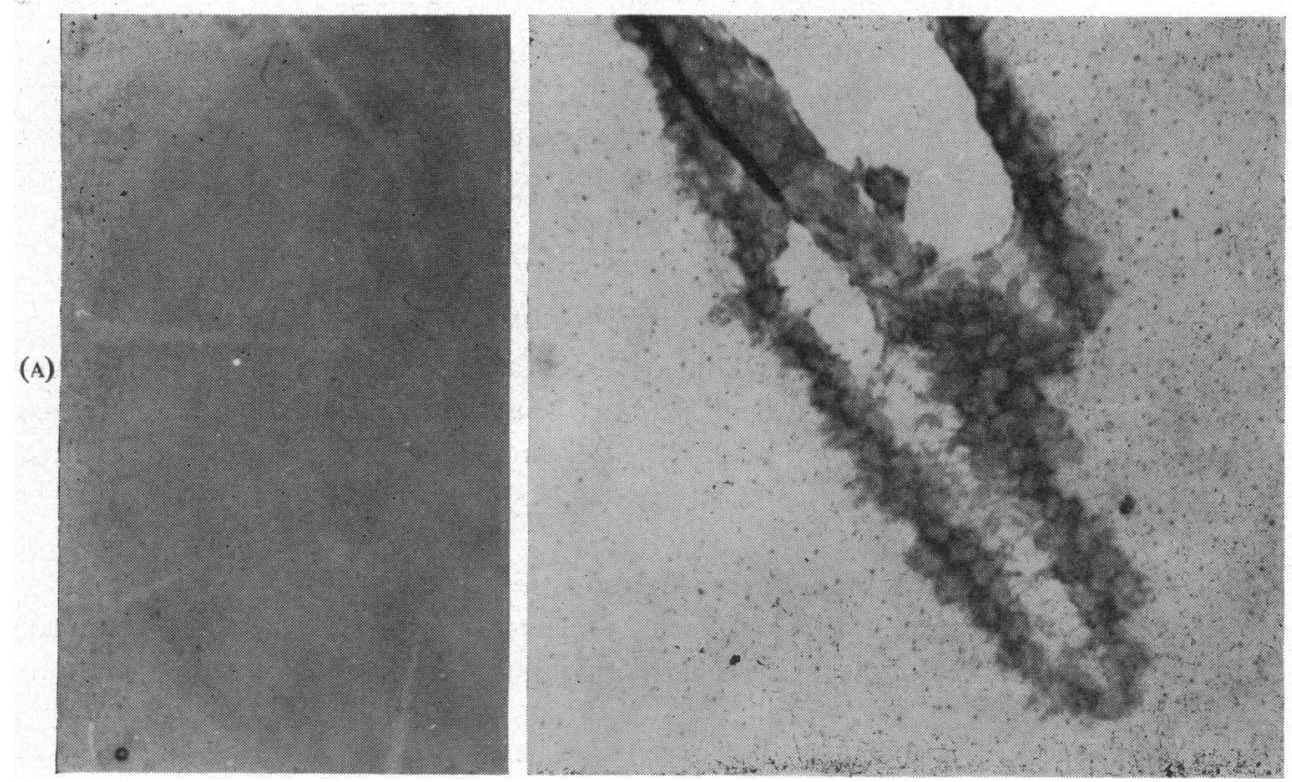

FIG. 1.-Endothelium examined by the nitroblue-tetrazolium technique, substrate $\beta-\mathrm{OH}$ butyrate.

(A) Endothelium of fresh canine corneal disc kept at $+18^{\circ} \mathrm{C}$. for 3 hours. $\times 13$.

(B) Photomicrograph of 1(A). Endothelium damaged by brush. Damaged endothelium stained. $\times 240$.

* For details of the staining medium: Mr. P. O’Neill, Eye Department, Westminster Hospital, London, S.W.1. 


\section{From Unfrozen Corneae Suspended in Media containing DMSO}

Pairs of donor eyes were again kept for 3 or 24 hours. The separated corneae were suspended at $+2^{\circ} \mathrm{C}$. for 6 minutes in media containing $8,10,12$, or 14 per cent. DMSO; they were gently washed, incubated, fixed, and mounted as usual.

Corneae stored for 3 hours differed in no way from corneae kept in vapour; a marked increase of stained endothelial cells was noticed in specimens which had been stored for about 24 hours before suspension in DMSO. Differentiation of specimens suspended in the four concentrations of DMSO could not be made with certainty in either of the two experimental series. The amount of dye in the cytoplasm of cells differed in no way from that already described in the series of fresh corneal donor material kept in vapour.

The results suggest that the four DMSO concentrations tested are non-toxic to endothelial cells of fresh cornea stored for 3 hours. It was decided to use similar concentrations of the protective agent and corneae kept for 3 hours in cooling experiments.

\section{From Frozen Corneae Suspended in Media containing 8, 10, 12, or 14 per cent. DMSO}

Cooled Suspended in $7 \mathrm{ml}$. Medium and Banked at $-197^{\circ} \mathrm{C}$.

THAWING IN WATERBATH AT $+50^{\circ} \mathrm{C}$.

Thawing was completed in 150 to 180 seconds and the final temperature of thawed-out medium was about $+25^{\circ} \mathrm{C}$.; specimens were subsequently transferred into stock-solution at $+20^{\circ} \mathrm{C}$. for a further 6 minutes.

Microscopical examination of the mounted specimens showed a dark-blue stained endothelium and revealed at least 80 per cent. stained endothelial cells. Cell loss was noticed in areas in which all endothelial cells stained heavily; areas in which cell destruction had taken place were found scattered over the endothelium of specimens. Outline of cells were in general regular, and diformazan granules were present in the entire cytoplasm or concentrated at the periphery of cells (see Fig. 2A and B, opposite). Differentiation between specimens cooled and suspended in the four concentrations of DMSO was not possible.

THAWING IN WATERBATH AT $+50^{\circ} \mathrm{C}$. AND BY DILUTION OF SUSPENDING MEDIUM

Open containers were put in a waterbath at $+50^{\circ} \mathrm{C}$. and seconds later $10 \mathrm{ml}$. stocksolution at $+15^{\circ} \mathrm{C}$. were added to the partly thawed-out medium surrounding the frozen cornea. Thawing was completed in about 110 seconds and the final temperature of fluid was +20 to $+25^{\circ} \mathrm{C}$; ; corneae were suspended in stock-solution at $+20^{\circ} \mathrm{C}$. for a further 6 minutes.

Examination of corneal endothelium showed reduction in the number of stained endothelial cells to about 60 per cent. in all specimens. Patches consisting of 100 per cent. stained cells were rarely seen and there was no loss of cells. Individual cells showed great variations in the amount of diformazan granules in their cytoplasm; in a number of cells diformazan granules surrounded cell nuclei and thus resembled stained cells of fresh corneae (see Fig. 3A and B, opposite).

Dilution of suspending medium, reduction in thawing time, and a lower final thawing temperature might all have played a part in obtaining better results in the second series. It was decided further to reduce the amount of suspending medium. 
FIGs 2-6.-Results of canine corneae suspended in medium containing 10 per cent. DMSO before cooling.
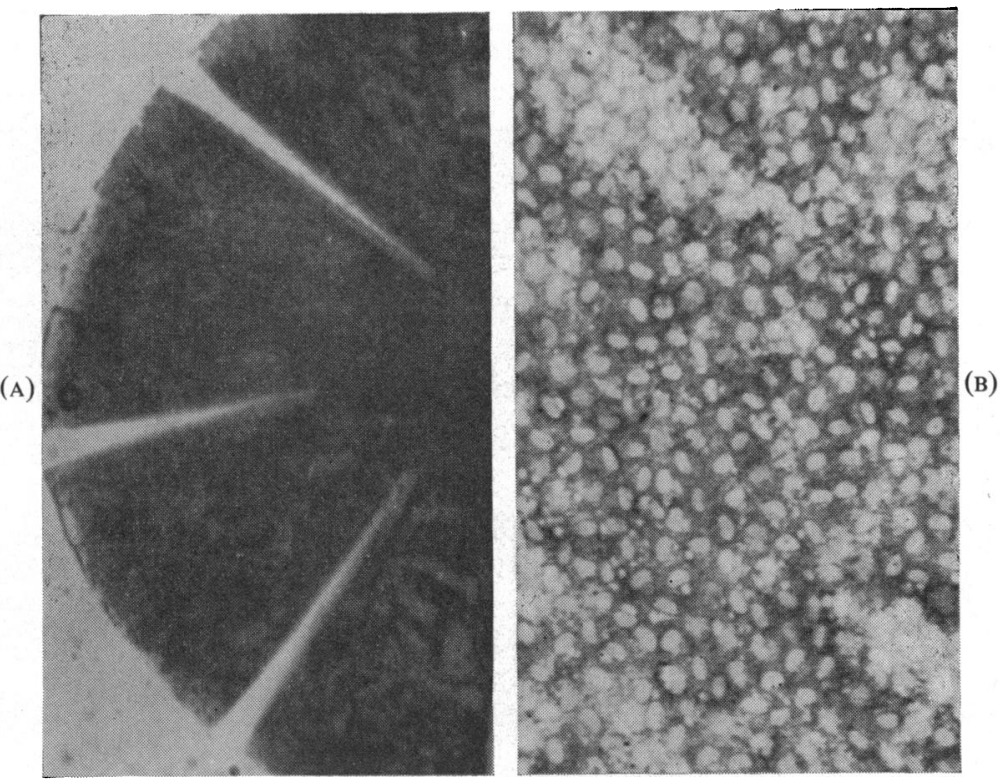

Fig. 2 (A) Endothelium of corneal disc kept in $7 \mathrm{ml}$. at $-197^{\circ} \mathrm{C}$. and thawed out in water bath. $\times 13$

(B) Photomicrograph of $2(A) . \quad \times 240$.
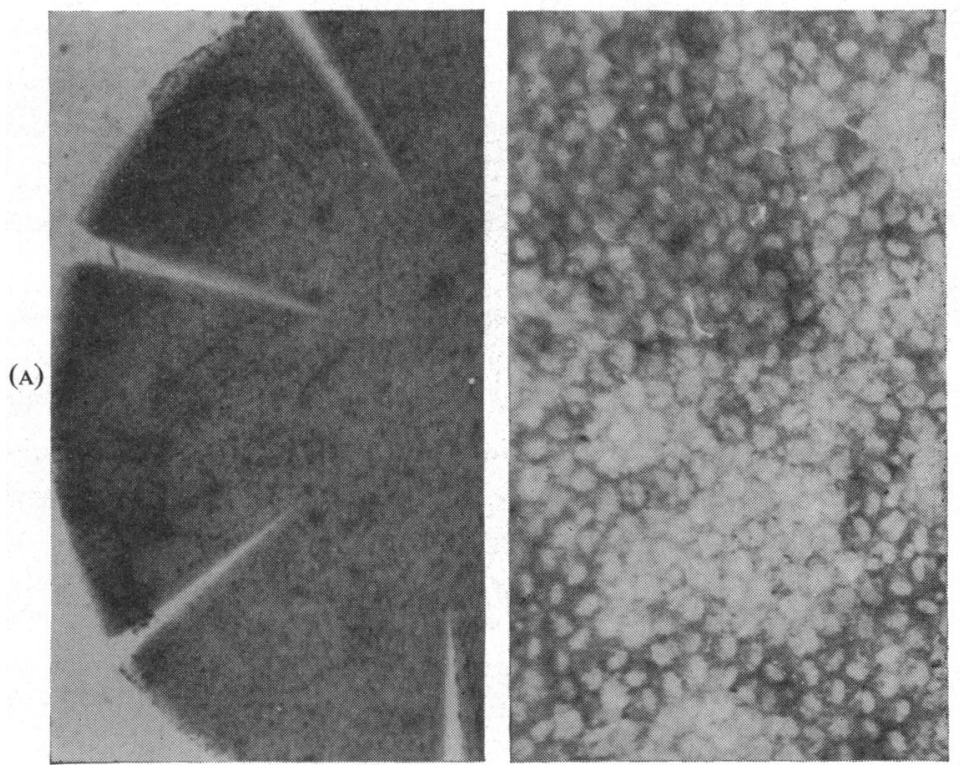

FIG. 3 (A) Endothelium of corneal disc kept in $7.0 \mathrm{ml}$. at $-197^{\circ} \mathrm{C}$. and thawed out in water bath and by dilution of medium. $\times 13$.

(B) Photomicrograph of 3(A). $\times 240$. 
Cooled Suspended in $0.5 \mathrm{ml}$. Medium and Banked at $-197^{\circ} \mathrm{C}$.

Containers were held in the hand during thawing, and when the ice began to melt $10 \mathrm{ml}$. stock-solution at $+10^{\circ} \mathrm{C}$. were added. All the ice had melted in less than 80 seconds and the fluid temperature was about $+10^{\circ} \mathrm{C}$.

The endothelium of mounted full-thickness discs showed a further reduction in the number of stained cells. In most specimens a central area about $4 \mathrm{~mm}$. in diameter showed an average of 30 per cent. stained cells; in a few specimens less than 10 per cent. stained endothelial cells were seen. The periphery of the $9 \mathrm{~mm}$. disc sometimes showed up to 80 per cent. stained cells. Observations revealed that the corneal centres thawed out faster than the periphery because of the larger amount of ice attached to the scleral rim (see Fig. 4A and B). In a few specimens the corneal centres showed a greater number of stained cells than the periphery of the discs. In these cases an air bubble was found trapped within the corneal concavity, a sheet of ice stretching behind the bubble across the scleral rim preventing its escape.

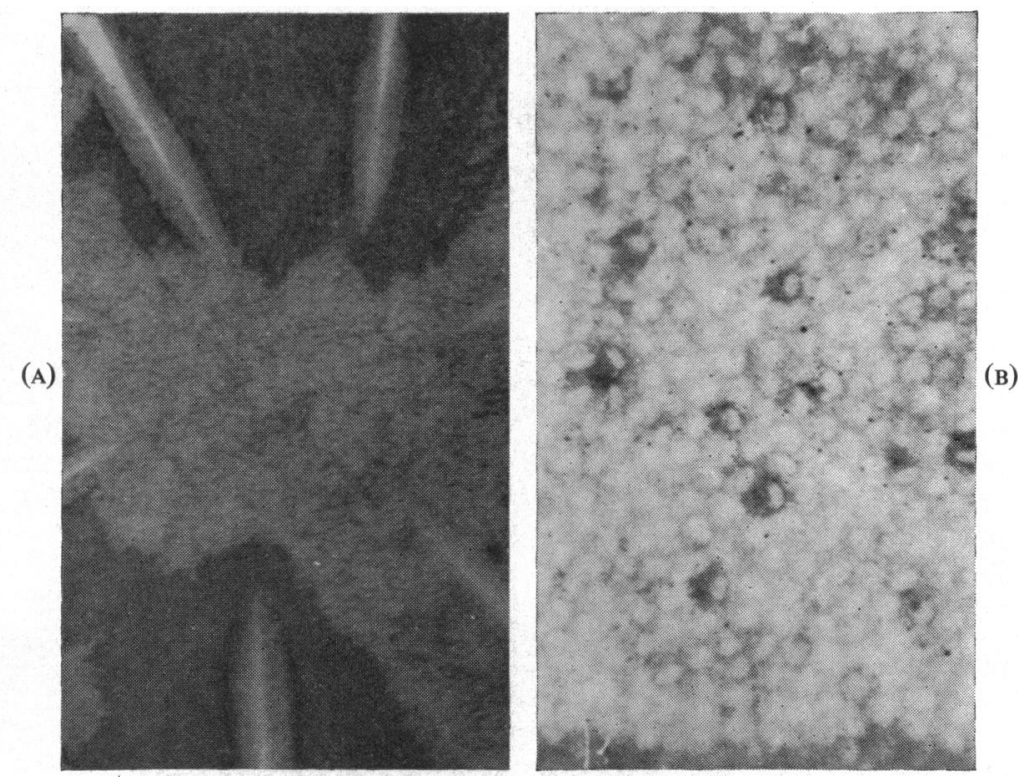

Fig. 4 (A) Endothelium of corneal disc kept in $0.5 \mathrm{ml}$. at $-197^{\circ} \mathrm{C}$. and thawed out in water bath and by dilution of medium. $\times 130$.

(B) Photomicrograph of 4(A). $\times 240$.

The appearance of the stained cells was similar to that of the cells already described, faintly staining cells being in the majority. Differentiation between corneae cooled suspended in one of the four media containing DMSO was impossible.

Cooled in Vapour and Banked at $-197^{\circ} \mathrm{C}$.

During thawing vessels were held in the bare hand and $10 \mathrm{ml}$. stock-solution of about $-6^{\circ} \mathrm{C}$. were quickly added.* In some instances the frozen and loose cornea was taken out of its container and placed into a vessel containing stock-solution. Both methods gave similar results. An average of 10 to 20 per cent. stained endothelial cells was found

- Thawing was completed in less than 60 seconds and the temperature was about $+8^{\circ} \mathrm{C} .^{\prime}$ 


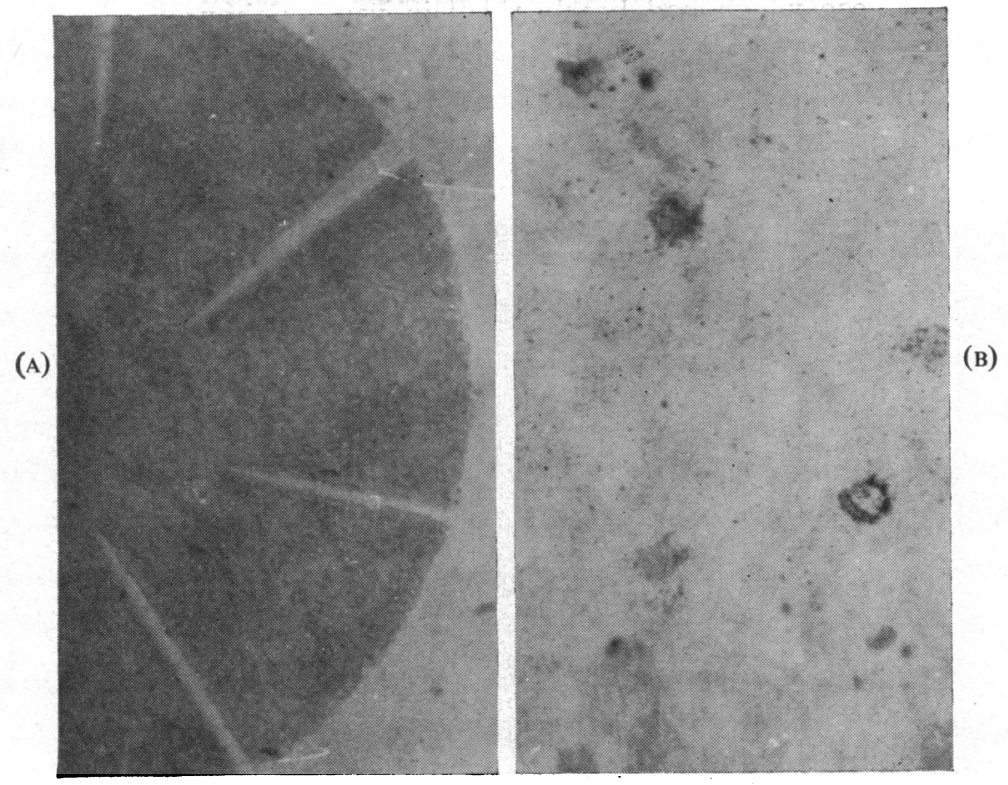

Fig. 5 (A) Endothelium of corneal disc kept in vapour at $-197^{\circ} \mathrm{C}$. and thawed out by resuspension. $\times 30$.

(B) Photomicrograph of $5(\mathrm{~A}) . \times 240$.

scattered over the endothelial surface; in large areas only very few stained cells were seen (see Fig. 5A and B).

Stained cells showed diformazan granules either evenly distributed within the cytoplasm or surrounding the cell nucleus. Corneae suspended in various concentrations of DMSO gave equally good results.

From Frozen Corneae Cooled and Suspended in Medium containing PVP and Protective Agent or Cooled in Vapour after Suspension.

Corneae were suspended in $10 \mathrm{ml}$. stock-solution containing 6 per cent. PVP 40 or PVP 10 and 8,10,12, or 14 per cent. DMSO; they were afterwards cooled in $7.0 \mathrm{ml}$. in $0.5 \mathrm{ml}$., or in vapour, and were thawed out by one of the techniques used in previous experiments. After the incubation and mounting of the specimens the endothelium was examined.

The results correspond with previous experimental series in which PVP had been omitted; corneae which had been cooled in vapour after suspension in one of the four concentrations of DMSO gave the best results.

\section{From Human Corneae Suspended in 10 or 14 per cent. DMSO}

Corneae of six pairs of donor eyes were suspended in $10 \mathrm{ml}$. stock-solution containing one of the above concentrations of the protective agent. The results of human corneae suspended in $7 \mathrm{ml}$. medium were similar to those of canine corneal tissue and 80 to 100 per cent. of endothelial cells stained heavily; cell loss was detected over central and peripheral parts in dark-blue stained areas in one of the six corneae examined. 
By contrast, corneae which had been cooled in vapour showed-after suspension in 10 or 14 per cent. DMSO-a great reduction in the number of stained endothelial cells (see Fig. 6A and B). The results are comparable with those obtained with canine tissue, but the number of eyes made available was too small for conclusions to be drawn.
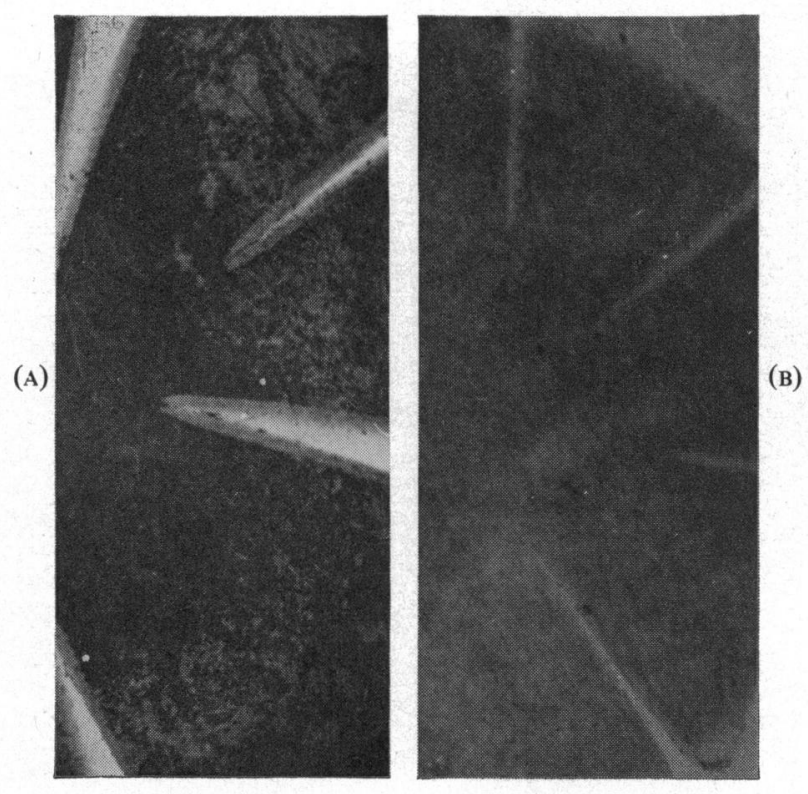

FIG. 6 (A) Endothelium of human corneal disc kept in $7 \mathrm{ml}$. at $-197^{\circ} \mathrm{C}$. and thawed out in water bath. $\times 13$.

(B) Endothelium of human corneal disc kept in vapour at $-197^{\circ} \mathrm{C}$. and thawed out by resuspension. $\times 13$.

\section{Discussion}

The techniques of cooling and thawing whole intact canine donor eyes present problems unknown when treating separated corneae. In preliminary experiments anterior chambers of intact donor eyes were irrigated with a medium containing 10 per cent. DMSO. This concentration was found to have been reduced to 2 per cent. DMSO when fluid was aspirated 30 minutes after irrigation. Unless irrigation is maintained for long periods the concentration of DMSO in the anterior chamber is inadequate for the protection of corneal endothelium because of the diffusion of the protective agent into the ocular tissues, especially into the vitreous humour. Injections of higher concentrations of DMSO over a short period proved to be too toxic to corneal endothelial cells.

Observations on thawing intact donor eyes had shown that after all the ice attached to the cornea had melted and all the ice in the anterior chamber had disappeared, recrystallization of ice often occurred which damaged endothelial cells. Freezing of the aqueous humour and cornea took place because of the low temperature of the ice in the lens and vitreous.

Careful dissection of corneae from donor eyes prevented all damage to endothelium, a $2 \mathrm{~mm}$. rim of sclera was adequate to handle specimens without gripping the endothelium. In spite of its 14 to $16 \mathrm{~mm}$. diameter the cornea of the dog when resting on its scleral rim maintained its physiological shape especially at a temperature of $+2^{\circ} \mathrm{C}$. The cornea of the rabbit was too thin whereas the cornea of the cat was too large in diameter and both 
specimens collapsed or became indented; the human cornea maintained its physiological shape.

Endothelial changes as detected by the nitroblue-tetrazolium technique are in part due to unknown factors. Equal numbers of stained cells were observed in the endothelium of corneae from one donor animal. In some instances DMSO caused greater damage than expected to the endothelial cells of donor eyes irrespective of its concentration. At other times the number of stained endothelial cells of pairs of corneae was surprisingly small when compared with the average number detected in corneae of a particular experiment.

Present indications are that PVP in 6 per cent. concentration does not give additional protection to the concentration of DMSO. Preliminary experiments in which a medium containing 6 per cent. PVP only was used did not show any protection of endothelial cells.

Survival of endothelium is not critically dependent on its cooling rate (O'Neill and others, 1967). The cooling rates of corneae suspended in either 7 or $0.5 \mathrm{ml}$. medium or in vapour were most likely to remain within the established ranges, in particular as metal containers were used which are better conductors than glass vials. The cooling of corneae in vapour was first suggested by Pegg (1965) and has proved to be most successful when assessing the viability of endothelium of thawed-out material by the nitroblue-tetrazolium technique. Overheating of corneae suspended in media containing DMSO often occurs; hot tap-water which is frequently used for thawing varies in temperature and glass vials have a high thermal capacity. The smaller the amount of suspension medium the greater the danger of overheating the specimen; 10 per cent. of $\mathrm{DMSO}$ at a temperature of $+40^{\circ} \mathrm{C}$. may cause considerable damage to the endothelium.

The technique of thawing corneae banked in vapour is easy to learn and quickly carried out, and entails no risk of overheating the specimen. The constant temperature of the hand replaces the varying temperature of the hot tap-water, and the lowest compartment of a household refrigerator provides the right temperature for the resuspension on medium. The temperature of the resuspension medium is not critical; the DMSO concentration in cells is reduced within seconds, a medium at about $+10^{\circ} \mathrm{C}$. proving to be satisfactory. During thawing the cornea is best kept resting on its scleral rim while fluid is added; under no circumstances must fluid be poured directly on to the endothelium. Corneae loose in their containers are best taken out quickly and then resuspended in the fluid in a second vessel. Resuspension and fast thawing of corneae appear to be important; specimens which wre left to thaw on the bench and without resuspension showed a great increase in the number of stained cells.

The examination of 315 stained corneae suggests better results with the dilution or resuspension of corneae during thawing, improvements with shorter thawing times, and with the lowest final temperatures. In practice thawing times and thawing temperatures will vary and may be harmful when high concentrations of DMSO are used. It would therefore be advisable to choose a DMSO concentration of low toxicity such as 8 or 10 per cent. which at the same time gives adequate protection against damage during cooling, banking, and thawing. The tentative conclusion that a decrease in the number of stained endothelial cells is synonymous with an improvement in a deep-freeze storage technique is supported by the results obtained when grafting fresh and frozen canine donor material which is to be the subject of a subsequent communication (Mueller, 1968). 


\section{Summary}

Corneae cut from canine donor eyes were cooled at similar rates in the presence of $8,10,12$, or 14 per cent. dimethylsulphoxide (DMSO); they were banked at $-197^{\circ} \mathrm{C}$. and thawed out at different rates to above zero temperatures. In order to obtain the various thawing rates, the technique of suspension of the corneae varied between experimental series.

Corneae were cooled and banked in 7.0 or $0.5 \mathrm{ml}$. of medium or in vapour, and five different techniques of thawing were tested. Corneae cooled in vapour gave the best results. During thawing the aluminium containers were held in the hand and the corneae banked in vapour were resuspended in $10 \mathrm{ml}$. DMSO-free stock-solution. The viability of the endothelium of fresh and frozen corneae was assessed by the nitroblue-tetrazolium technique.

I wish to thank the Medical Research Council and Mr. P. D. Trevor-Roper, F.R.C.S., for their support. I am particularly grateful to the Principal and Dean, Sir John N. Ritchie, C.B.E., F.R.C.V.S., to Professor C. Formston, F.R.C.V.S., and to Professor E. C. Amoroso, F.R.S., for allowing me to work at the Royal Veterinary College, Camden Town. It is a pleasure to acknowledge the help of Dr. D. E. Pegg and of Mr. M. R. Young at the National Institute for Medical Research, Mill Hill. Mr. O'Neill and his technician supplied the nitroblue-tetrazolium stain.

\section{REFERENCES}

Capella, J. A., Kaufman, H. E., and Robeins, J. E. (1965). Arch. Ophthal. (Chicago), 74, 669.

Eastcott, H. H. G., Cross, A. G., Leigh, A. G., and North, D. P. (1954). Lancet, 1, 237.

HénAFr, F. (1960). In "Recent Research in Freezing and Drying", ed. A. S. Parkes and A. U. Smith, p. 295. Blackwell Scientific Publications, Oxford.

Kaufman, E. H., Escapini, H., Capella, J. A., Robbins, J. E., and Kaplan, M. (1966). Arch. Ophthal. (Chicago), 76, 471.

KING, J. H. (1958). Trans. Amer. ophthal. Soc., 56, 203.

LOVELOCK, J. H., and BisHOP, M. W. H. (1959). Nature (Lond.), 183, 1394.

MUELLER, F. O. (1968). Brit. J. Ophthal., 52, 752.

CAseY, T. A., and Trevor-Roper, P. D. (1964). Brit. med. J., $2,473$. , O'NemL, P., and TreVor-ROPER, P. D. (1967). Brit. J. Ophthal., 51, 227. and SмrTH, A. U. (1963). Exp. Eye Res., 2, 237.

O'Neill, P., Mueller, F. O., and TreVoR-RoPer, P. D. (1967). Brit. J. Ophthal., 51, 13.

Pearse, A. G. E. (1960). "Histochemistry, Theoretical and Applied", 2nd ed. Churchill, London.

PegG, D. E. (1965). Personal communication.

RYCROFT, B. W. (1957). Brit. J. Ophthal., 41, 759.

Smith, A. U., Ashwood-Smith, M. J., and Young, M. R. (1963). Exp. Eye Res., $2,71$.

Stocker, F. W., Matton, M. Th., Eiring, A., Georgiade, R., and Georgiade, N. (1960). Amer. J. Ophthal., 49, 729.

SweEBe, E. C., and Dohlman, C. H. (1961). Arch. Ophthal. (Chicago), 66. 343. 